\title{
Lifestyle factors and serum androgens among 636 middle aged men from seven countries in the European Prospective Investigation into Cancer and Nutrition (EPIC)
}

\author{
Reiko Suzuki $\cdot$ Naomi E. Allen $\cdot$ Paul N. Appleby $\cdot$ Timothy J. Key $\cdot$ \\ Laure Dossus · Anne Tjønneland · Nina Føns Johnsen · Kim Overvad · \\ Carlotta Sacerdote · Domenico Palli · Vittorio Krogh • Rosario Tumino · \\ Sabine Rohrmann · Jakob Linseisen · Heiner Boeing • Antonia Trichopoulou • \\ Georgios Makrygiannis · Gesthimani Misirli · H. Bas Bueno-de-Mesquita • \\ Anne M. May · María José Tormo Díaz · Maria-José Sánchez • \\ Aurelio Barricarte Gurrea · Laudina Rodríguez Suárez • Genevieve Buckland • \\ Nerea Larrañaga $\cdot$ Sheila Bingham $\cdot$ Kay-Tee Khaw $\cdot$ Sabina Rinaldi · \\ Nadia Slimani · Mazda Jenab · Elio Riboli · Rudolf Kaaks \\ Published online: 25 April 2009 \\ (C) Springer Science+Business Media B.V. 2009
}

\section{Erratum to: Cancer Causes Control DOI 10.1007/s10552-009-9326-y}

Under the Statistical analysis section, the second starting sentence should be read as "Partial correlation coefficients with adjustment for age at blood collection, laboratory batch, center and BMI were used to ...."

The online version of the original article can be found under doi:10.1007/s10552-009-9326-y.

R. Suzuki · N. E. Allen · P. N. Appleby · T. J. Key Cancer Epidemiology Unit, Nuffield Department of Medicine, University of Oxford, Oxford, UK

\section{R. Suzuki ( $\square)$}

Division of Epidemiology and Prevention, Research Center for Cancer Prevention and Screening, National Cancer Center, Tukiji 5-1-1, Chuo-ku, 104-0045 Tokyo, Japan

e-mail: resuzuki@ncc.go.jp

L. Dossus · S. Rohrmann · J. Linseisen $\cdot$ R. Kaaks Division of Cancer Epidemiology, German Cancer Research Centre (DKFZ), Heidelberg, Germany

\section{A. Tjønneland · N. Føns Johnsen}

Institute of Cancer Epidemiology, Danish Cancer Society,

Copenhagen, Denmark

\section{K. Overvad}

Department of Clinical Epidemiology, Aarhus University

Hospital, Aalborg, Denmark

C. Sacerdote

CPO-Piemonte and ISI Foundation, Torino, Italy
Third para of Result section, should read as "Partial correlations between log-transformed androgen concentrations, adjusted for age, batch, center and BMI, are shown in Table 2. Statistically significant positive associations $(p<0.01)$ were observed between all hormones, except between SHBG and each of A-dione and FT. The correlation between SHBG and A-diol-g was of borderline statistical significance $(p=0.01)$."

\author{
C. Sacerdote \\ Unit of Cancer Epidemiology, University of Turin, Turin, Italy \\ D. Palli \\ Molecular and Nutritional Epidemiology Unit, Cancer Research \\ and Prevention Institute (ISPO), Florence, Italy \\ V. Krogh \\ Nutritional Epidemiology Unit, Fondazione IRCCS Istituto \\ Nazionale dei Tumori, Milan, Italy \\ R. Tumino \\ Cancer Registry, Azienda Ospedaliera "Civile M.P. Arezzo", \\ Ragusa, Italy \\ H. Boeing \\ Department of Epidemiology, German Institute of Human \\ Nutrition Potsdam-Rehbruecke, Nuthetal, Germany \\ H. Boeing \\ Department of Urology, Charité-University Medicine Berlin, \\ Berlin, Germany
}


A. Trichopoulou · G. Makrygiannis · G. Misirli Department of Hygiene and Epidemiology, University of Athens Medical School, Athens, Greece

H. B. Bueno-de-Mesquita · A. M. May

National Institute for Public Health and the Environment (RIVM), Bilthoven, The Netherlands

\section{J. T. Díaz}

Epidemiology Department, Murcia Health Council, Murcia, Spain

M. J. T. Díaz · M.-J. Sánchez · A. Barricarte Gurrea CIBER Epidemiología y Salud Pública (CIBERESP), Barcelona, Spain

M.-J. Sánchez

Andalusian School of Public Health, Granada, Spain

\section{A. Barricarte Gurrea}

Public Health Institute of Navarra, Pamplona, Spain

L. Rodríguez Suárez

The Public Health Directorate, Asturias, Spain

G. Buckland

Unit of Nutrition, Environment and Cancer, Cancer

Epidemiology, Research Programme, Catalan Institute

of Oncology (ICO), Barcelona, Spain
N. Larrañaga

Epidemiology Unit, Basque Health Department in Gipuzkoa, San Sebastian, Spain

S. Bingham

Department of Public Health and Primary Care, MRC Centre for Nutritional Epidemiology in Cancer Prevention and Survival, Cambridge, UK

K.-T. Khaw

Department of Gerontology, University of Cambridge, Cambridge, UK

S. Rinaldi · N. Slimani $\cdot$ M. Jenab International Agency for Research on Cancer (IARC-WHO), Lyon, France

E. Riboli

Department of Epidemiology and Public Health, Imperial College London, London, UK 